\title{
El valor sensible de la artesanía en el diseño
}

Rosario Velasco Aranda* Universidad de Granada. España

RECIBIDO: 21.12.2015 / ACEPTADO: 10.02.2016

\section{Resumen}

El diseño ahora es consciente de lo útil que le es el mutualismo con la artesanía, y a ésta le proporciona nuevos modelos de pervivencia, favoreciendo interesantes desarrollos y evoluciones. Este sensible fenómeno de revalorizar objetos y sistemas productivos, que han sobrevivido a lo largo de años, décadas y siglos, junto con una revisión contemporánea en su diseño, empieza a adquirir visibilidad, notoriedad. Cada vez más se demuestra el interés que adquieren estas aportaciones al mundo del producto. Este artículo ejemplifica este sensible fenómeno reflexionando sobre la empresa Nanimarquina.

Palabras clave: artesanía, diseño, producto, tendencia.

\section{Close Relatioship between Craft and Design}

\begin{abstract}
The world of design is now aware of how useful its mutualism with crafts is, giving to the last one new models of survival and promoting interesting ways of development and evolution. The fact of valuing objects and productive systems that have survived over the years, decades and centuries, along with a contemporary review in design, is gaining visibility and notoriety; this liaison is increasingly acquiring a notable interest and its contribution to the product design field is a fact already. This article explains the close relationship between craft and design, showing the company Nanimarquina as a model of it.
\end{abstract}

Keywords: craft, design, product, trend.

\begin{abstract}
Vosotros, cuyas manos hacen aquellas cosas que deberían ser obras de arte, debéis ser todos artistas, y buenos artistas además, antes de que el público en general pueda sentir un interés real por tales cosas; (...) el artesano, dejado atrás por el artista cuando las artes se separaron, debe ponerse a la altura de éste, debe trabajar codo con codo con él...
\end{abstract}

William Morris, The Lesser Arts

Cuando pensamos en artesanía es fácil que la mente recurra a imágenes comunes de nuestra experiencia, y veamos, por ejemplo, una serie de puestos a lo largo de una calle peatonal o plaza céntrica, donde dispares artesanos nos ofrecen los más variopintos productos de sus quehaceres manuales, así pulseras, bolsos, monederos, platerías, pañuelos pintados, o figurillas de hojalata reciclada. 
Si insistimos un poco más, quizá, nos alejamos de la gran ciudad, para adentrarnos en la rústica tienda de cualquier pueblo recóndito, allí identificamos con mayor claridad la relación propia de una concreta artesanía con su lugar de origen. Ahora pensamos más claramente en la cerámica, el cuero, los textiles, la madera, la anea...

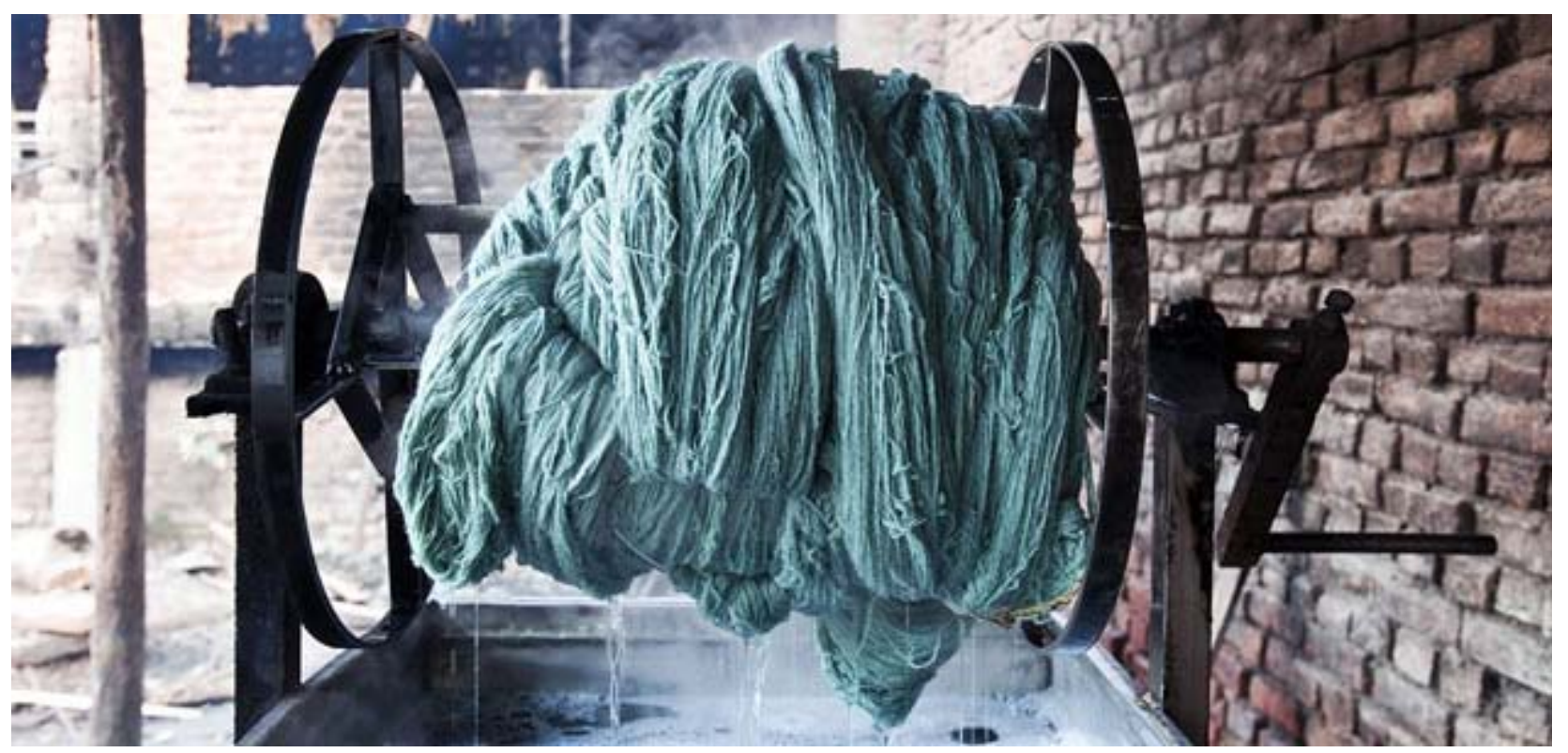

Fig. 1. Imagen ambientación sobre cultura de las alfombras, teñido de lana.

En estos caminos mentales relacionamos los objetos con sus funciones, materiales, aspectos estéticos, medio, orígenes... Y pareciera que, llegados a este punto con cierto nivel de profundidad en el análisis de esta visualización, pensáramos en lo artesano como algo atávico, parte de la historia de nuestra tradición productiva.

Sin embargo, fracturada la necesidad de estos objetos, por la insistente producción fabril y su capacidad evolutiva para la promoción del consumo, la artesanía se nos sugiere relegada al campo de lo testimonial y de lo decorativo, en un término muy distante del común de los canales productivos y distributivos del mercado actual, que propone una súper oferta de objetos consumibles altamente inteligentes en el diseño de las necesidades a detentar.

Despojada, a la artesanía se le ha concedido conservar el aura mística de lo ancestral, trabajado y único, al tiempo que, una práctica denostada y maltrecha por el desgaste de su explotación como souvenir, la aleja de otra supervivencia más exitosa.

Pero podemos ya detectar casos disconformes, propuestas que invierten el fenómeno, y le devuelven a la artesanía, en nuevo modo y forma, lo mismo que le usurparon. Hablamos del diseño. Sí, del mismo diseño que, en su concepción y desarrollo, en su relación productiva y mercantil, en su ego como actor del consumo contemporáneo, contribuyó al destierro de lo artesanal. 


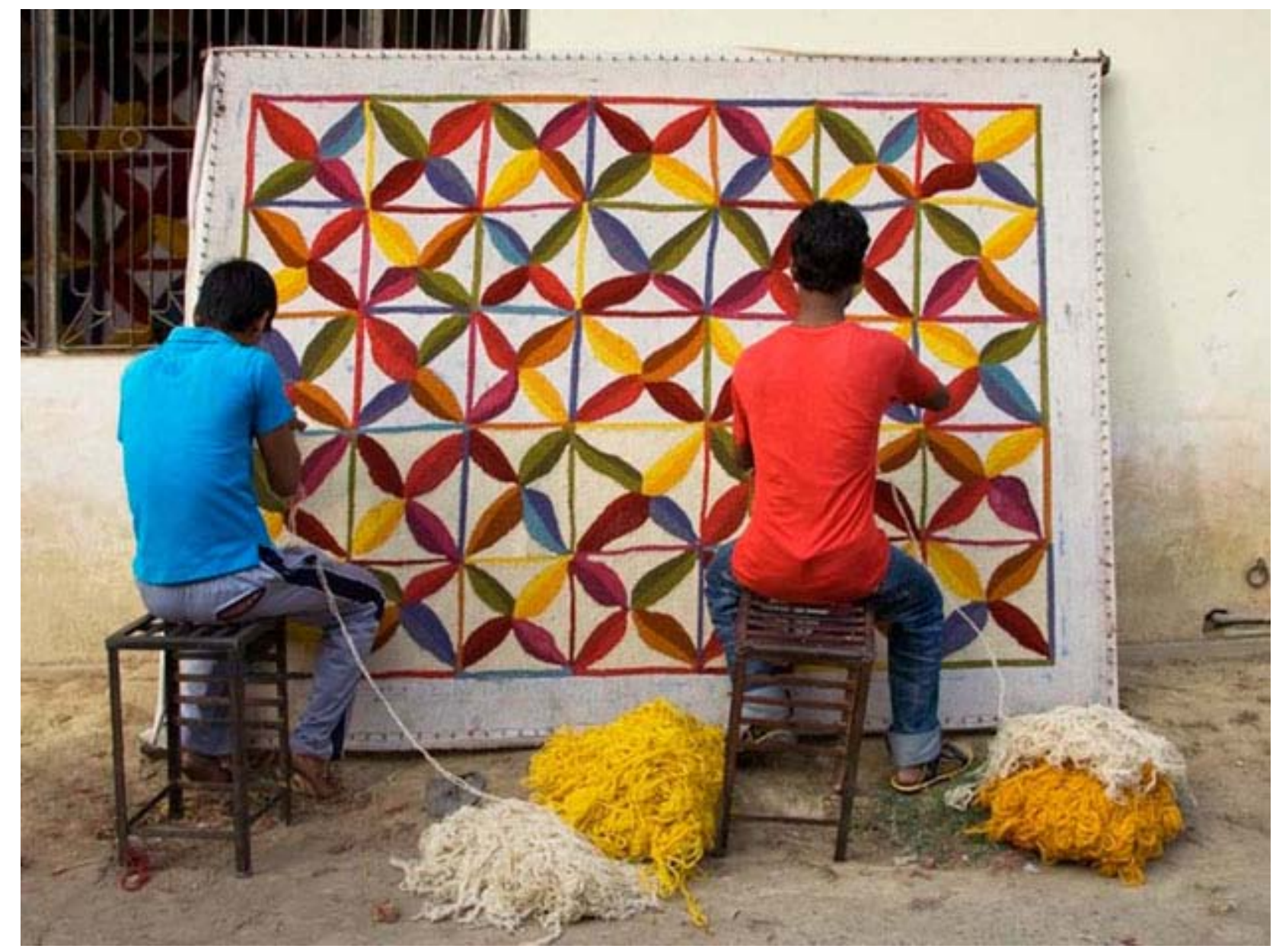

Fig. 2. Proceso de producción en lienzo de la alfombra de la colección Kala.

Para los que nos relacionamos con las artes aplicadas, en categorías como el diseño o la ilustración, es interesante observar y reconocer la labor de empresas y proyectos que reubican a la artesanía como sector productivo competente en el mercado. Somos conscientes de la sensibilidad del consumidor hacia este tipo de productos, apreciamos el potencial sensible, emocional y comunicativo del objeto artesanal. Productos que nos trasmiten sensaciones, historias, culturas, ideas, tradiciones, vanguardias... Nos aportan experiencias, experiencia de usuario, experiencia vivida, nos aportan maneras de hacer, ver y sentir la cultura. Nos relacionamos con los objetos materiales y espacios en los que nos desenvolvemos. Vemos desarrollarse procesos de identificación a través de ciertos productos que nos ayudan a hablar de nosotros y construyen nuestra identidad, nuestra realidad. Con ello, valoramos éstos como testigos y actores de la sociedad y la cultura.

El diseño ahora es consciente de lo útil que le es el mutualismo con la artesanía, y a ésta le proporciona nuevos modelos de pervivencia, y favorece interesantes desarrollos y evoluciones. Este sensible fenómeno de revalorizar objetos y sistemas productivos que han sobrevivido a lo largo de años, décadas y siglos, junto con una revisión contemporánea en su diseño, empieza a adquirir visibilidad y notoriedad. Cada vez más se demuestra el interés que adquieren estas aportaciones al mundo del producto. 


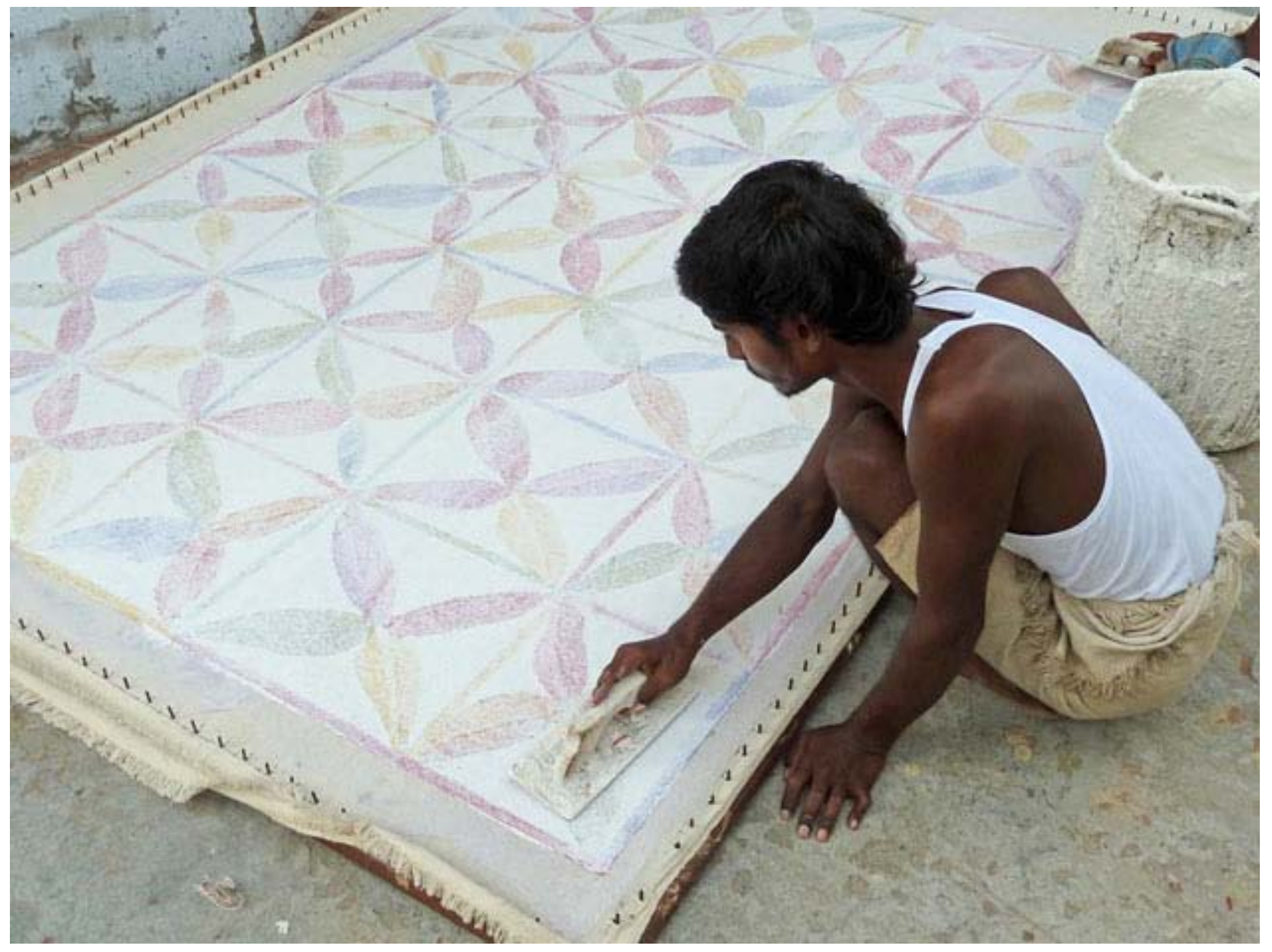

Fig. 3. Aplicación de látex natural en la parte trasera para la fijación del pelo en la técnica hand tufted.

El mejor ejemplo es la firma Nanimarquina, por ser ésta una empresa que conocemos desde dentro. Trabajando en ella hemos desarrollado numerosos proyectos, y actualmente continuamos colaborando. Es un proyecto que entendemos y compartimos en sus idearios, y al que se tien e un considerable aprecio y cariño, como parte del propio desarrollo profesional.

Nanimarquina es una empresa de reconocido nombre y prestigio en todo el mundo. Es una marca de producto que, con casi 30 años a sus espaldas, no ha parado de innovar, mayoritariamente, en el campo de las alfombras. Sin duda su gran aportación, su valor diferencial, es esa perfecta unión entre artesanía y contemporaneidad. Se trata de una empresa creativa e innovadora que explora los sistemas de producción artesanales y los revaloriza a través del diseño más vanguardista. El tándem entre la innovación y la artesanía más ancestral, hacen de perfecto eslabón para la creación y éxito de sus productos.

La empresa nace en 1987 como marca que apuesta por el valor del diseño en el campo de los textiles. Desde sus inicios plantea productos que prestan especial atención a la investigación de las materias primas y a los procesos de fabricación. Las primeras creaciones fueron series de alfombras diseñadas por la propia Nani Marquina, con formas geométricas y vivos colores muy acordes con la estética de los años ochenta. En 1993 Nanimarquina traslada su producción a India buscando mejorar el nivel de calidad de sus recursos productivos. La cultura local y el oficio de aquellos artesanos despertaron una nueva manera de hacer, de ser y pensar la empresa, que se sensibilizaría ante un fantástico sistema productivo basado en el concepto del valor artesanal. Desde entonces Nani Marquina se embarcaría en un continuo viaje, visitando y trabajando con 
distintos países, donde el uso y producción de alfombras son símbolo de origen, historia y cultura, buscando y experimentando con técnicas tradicionales, telares, soportes, materiales, fibras, diferentes torsiones de hilos, sistemas de anudados... Antiquísimos recursos que vislumbraría como potenciales para la renovación de este objeto de uso y consumo.

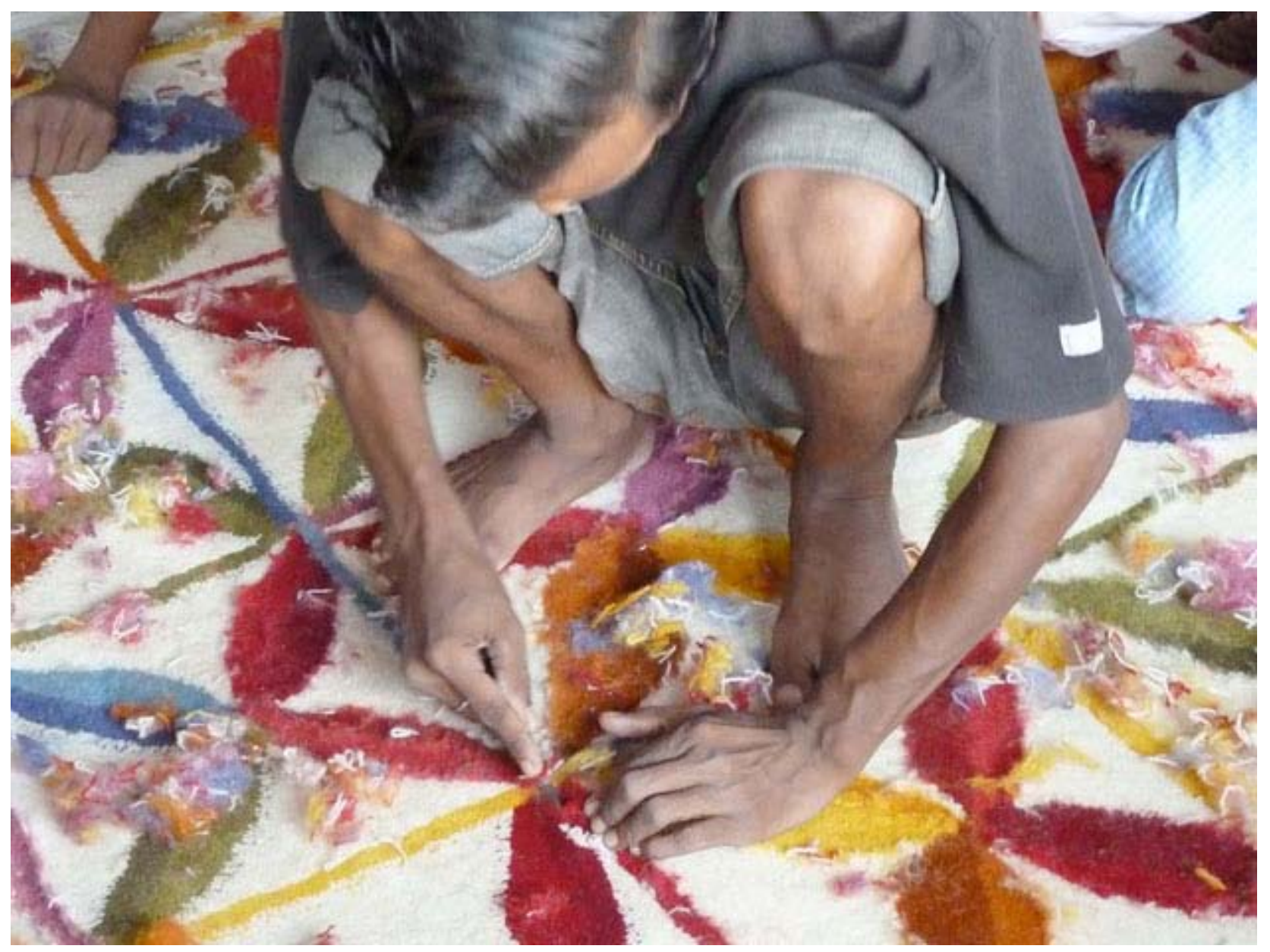

Fig. 4. Separación de las fibras, proceso de definición del dibujo.

La empresa es receptora e impulsora de energías creativas que innovan sobre la alfombra. Nanimarquina trabaja y colabora con diseñadores reconocidos al tiempo que apuesta por diseñadores noveles. De esta manera garantiza la diversidad y variedad en las formas de entender la alfombra. Supone una importante aportación en cuanto a los motivos y estéticas aplicadas sobre este tipo de producto. La alfombra, como pieza de interiorismo, como objeto doméstico, había sufrido cierta depreciación, tanto por ser un objeto artesanal sin revisión en sus diseños, como la suplantación de producciones mecanizadas que sustituyeron el consumo de alfombras en favor, por ejemplo, de las moquetas. Hoy, la aplicación de un concepto contemporáneo de diseño sobre esta naturaleza de productos genera un efecto de simbiosis entre lo artesanal y el fenómeno de las últimas tendencias.

Cuando devolvemos a la artesanía la acción sobre un diseño, concebido para su fabricación seriada, éste se inunda de valores sensibles, humanos. La perfección y el cuidado, la atención al detalle, la conciencia de la experiencia del producto, el oficio heredado de evoluciones ancestrales, así como las pequeñas variaciones propias del accidente en el trabajo manual y de las condiciones 
de productos naturales, otorgan ese valor diferencial y único que rezuma en cada pieza, y que constituye, en definitiva, un valor de marca.

Este valor se extrapola en cualquiera de las estancias donde tenga presencia una alfombra Nanimarquina. Imprime su carácter e influye en el resto del espacio donde se ubica. La alfombra ordena y reubica espacios, los invade, se acomoda a ellos, en torno a ella se distribuyen otros mobiliarios, y produce, en suma, una experiencia sensible, individual y compartida. La experiencia del usuario en una estancia con alfombra se ve gratamente alterada, le aporta confort, se presta a relacionarse con ella, a pisarla, a reposar sobre ella, nos da cobijo, nos aísla, todo esto revierte, aumenta, e incluso genera, nuevos valores emocionales.

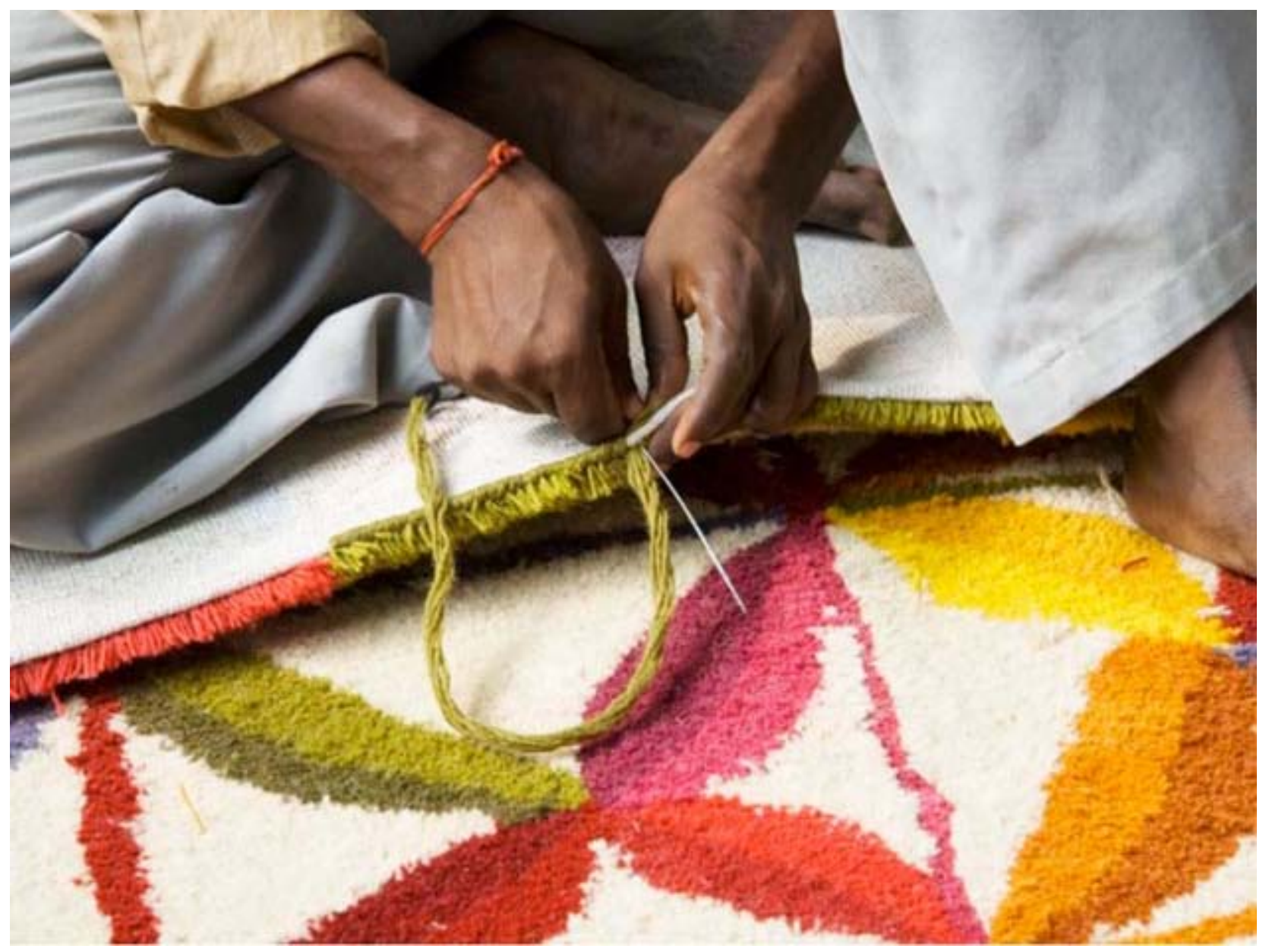

Fig. 5. Cosido del borde incorporar el backing.

Estas alfombras son objetos que enamoran. Los colores, texturas y diseño de sus motivos tienen una fuerte influencia en ese estado emocional. No nos limitamos a usar el producto, nos aporta experiencias vitales, produce sensaciones, momentos, recuerdos... En definitiva, nos hace sentir mejor y nos hace ser conscientes de ello. Todos éstos son valores de la marca Nanimarquina, y son valores destacables para el mundo del diseño actual. Aunar tradición y vanguardia, promover la calidad, la belleza y la innovación, ser conscientes del valor emocional y sensible de los objetos que creamos y con los que convivimos, ser responsables en la implicación de los actores productivos; y actuar, en definitiva, en la conciencia y criterios que desarrollan los consumidores. 


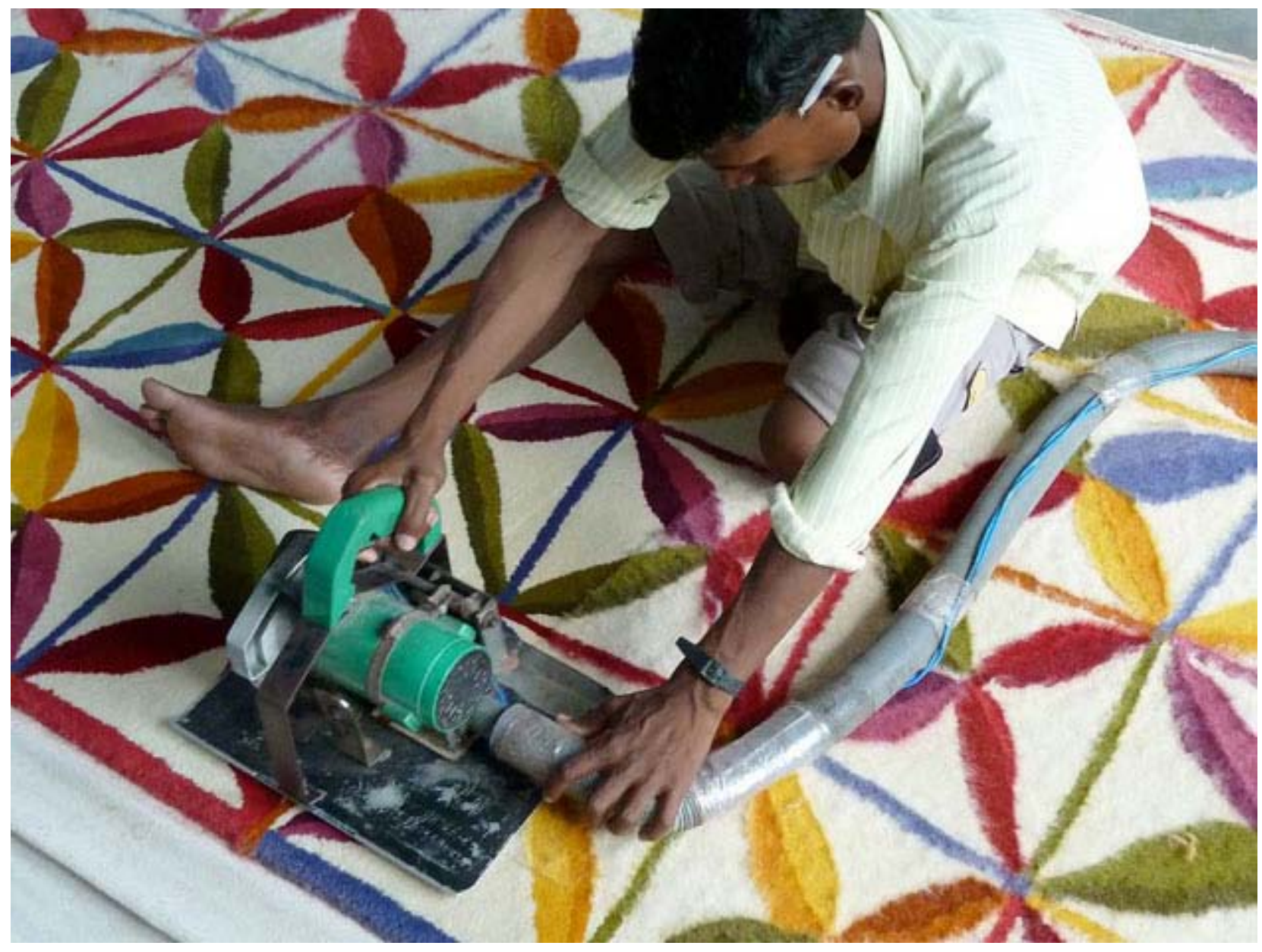

Fig. 6. Terminación de la alfombra por rasurado para nivelar la altura de pelo.

Como resumen recogemos las ideas expresadas por la propia Nani Marquina en el catálogo de producto del año 2009:

Ideas que hacen espacios

La edición de este catálogo anual supone la siempre buena oportunidad para pensar, entender, dar a conocer y reforzar las coordenadas esenciales que guían Nanimarquina.

El espíritu contemporáneo y las manufacturas tradicionales. La capacidad de absorber diferentes contextos naturales y culturales. La investigación del trabajo y el equipo. El compromiso con la excelencia de la gestión y la sensibilidad para contribuir a hacer un mundo mejor. La ilusión de su creatividad. Las sensaciones.

De todo ello se nutre Nanimarquina y todo ello se transforma en un reto estimulante: hacer crecer las ideas que conecten con las personas, con sus entornos y sus vidas. Esto es una alfombra, una oportunidad de definir el espacio que nos es propio.

Ahora y aquí, Nanimarquina presenta más de 50 ideas. Colecciones, series, diseños, motivos. Alfombras únicas. Junto con ellas, un conjunto de complementos y objetos cotidianos redondean la personalidad de una marca que quiere acercar el hogar actual a la autenticidad de los orígenes. 


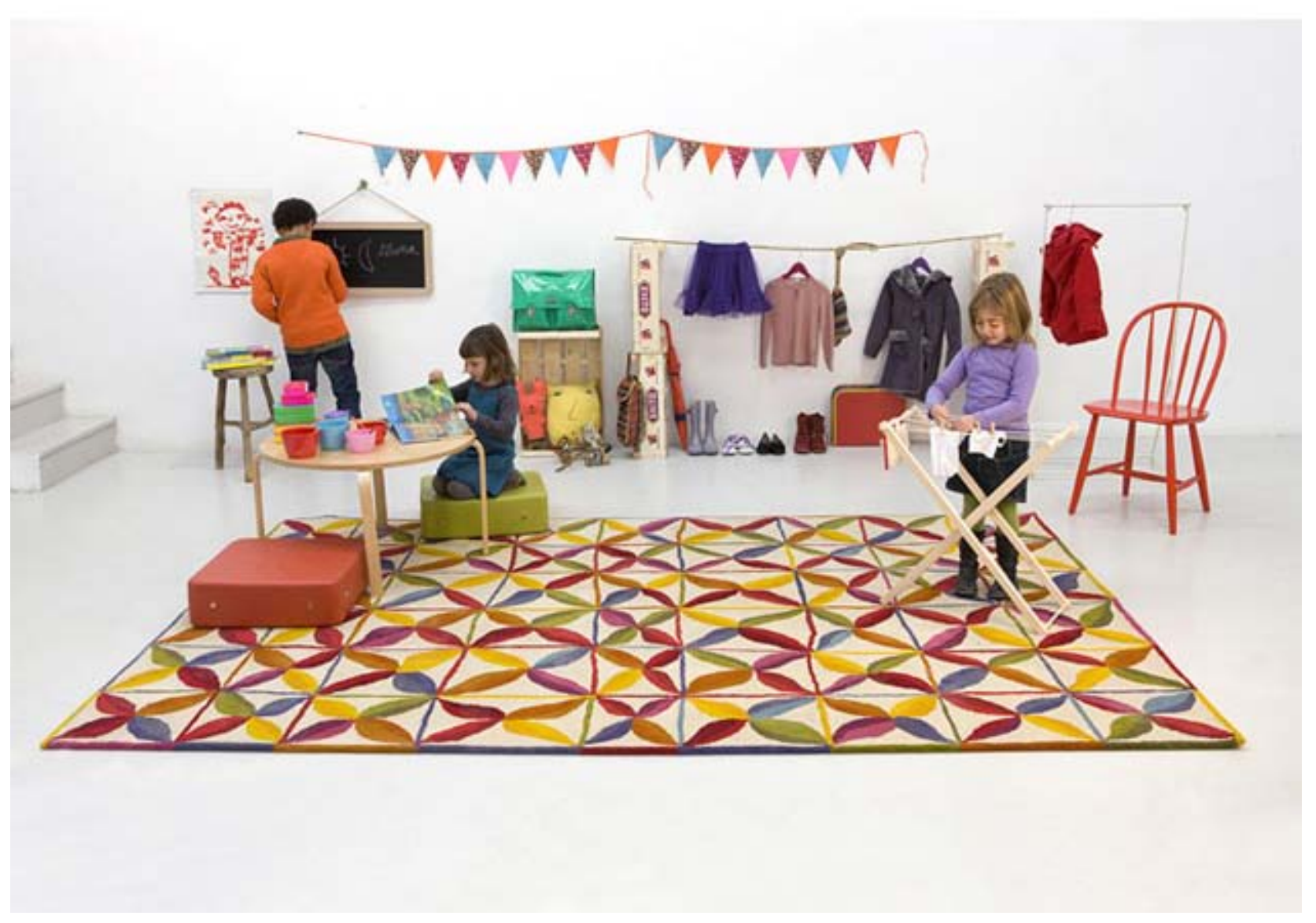

Fig. 7. Fotografía de ambientación para el catalogo de la empresa. Fibra 100\% Lana Nueva Zelanda. Técnica Hand tufted Densidad 56.000 nudos/m2. Altura pelo $14 \mathrm{~mm}$. Altura total 20 mm. Peso 4,50 kg/m2.

*Rosario Velasco Aranda es ilustradora y diseñadora autónoma. Su carrera profesional se ha ido ampliando en profundidad, en el mundo del diseño, en sus distintas aplicaciones, trabajo en publicidad, estampación textil, prensa, diseño de producto e interiorismo. Colabora con varios estudios de diseño, agencias, editoriales... Aparte de su trayectoria profesional como diseñadora e ilustradora, dedica gran parte de su tiempo a la formación en la docencia universitaria, y a la actividad investigadora. Correo-e: rosariova@ugr.es

\section{BIBLIOGRAFÍA}

GOMBRICH, E. H. El sentido del orden. Estudio sobre la psicología de las artes decorativas, Gustavo Gili, Barcelona 1980, p. 62.

CALVERA, A. (ed.). Arte ¿? Diseño, Gustavo Gili, Barcelona 2003.

CAMPI, I. La idea y la materia. Vol. 1: El diseño de producto en sus orígenes, Gustavo Gili, Barcelona 2007.

\section{IMÁGENES}

Fotografías: Albert Font. Destino: Cedida por la empresa. 